\title{
Evolución, espacios y contenidos del archivo y de la librería musical de la catedral de Burgo de Osma
}

\author{
Development, spaces and contents of the archive and \\ music library of the cathedral of Burgo de Osma
}

José Ignacio PALACIOS SANZ

Universidad de Valladolid

joseignacio.palacios@uva.es

\begin{abstract}
The archive and library of the cathedral of Burgo de Osma (Soria) is one of the most important elements in this institution, because it helps us to know and study its history. They were located in several rooms around the cloister until they were placed in the upper east wing, divided into two different halls, and the collections of music had no special space until a few decades ago. During the medieval and Renaissance period, the prelates were directly concerned about building up the collections in the Chapter Library and carrying out inventories. This was one of the most important archives in the national panorama, although it suffered various ups and downs, and some of its volumes and sheet music have been lost since the 17th century.
\end{abstract}

Keywords: Library; music archive; copyist; score; choir book.
Resumen: El archivo y biblioteca de la catedral de Burgo de Osma (Soria) es uno de los elementos más importante de esta institución porque nos ayuda a conocer y estudiar su historia. Estuvieron ubicados en varias dependencias en torno al claustro hasta que quedaron asentadas en el ala superior este, repartido en dos estancias diferenciadas, sin que los fondos musicales tuvieran un espacio específico hasta hace unas décadas. Durante el periodo medieval y renacentista los prelados se preocuparon directamente de dotar de importantes fondos a la biblioteca capitular y de realizar varios inventarios. Fue uno de los archivos más importantes en el panorama nacional, aunque sufrió diversos avatares y una pérdida de parte de sus volúmenes y partituras desde el siglo XVII.

Palabras clave: Biblioteca; archivo de música; copista; partichela; cantoral.

\section{INTRODUCCIÓN}

Este trabajo pretende presentar una descripción de los distintos espacios que ha ocupado el archivo y la biblioteca de la catedral de Burgo de Osma, así como de los fondos librarios y musicales que custodia desde época medieval hasta nuestros días. Las fuentes conservadas nos informan de la vida catedralicia, de la actividad musical y del apoyo que recibió por parte de obispos y mecenas. $\mathrm{Al}$ mismo tiempo, se ha investigado la producción y movilidad del repertorio, aparte de la actividad profesional y comercial de los copistas, encuadernadores y libreros de la 
música cantollanista y polifónica, a veces en estrecha relación con lo que realizan otros cabildos.

En este estudio también tienen cabida los inventarios, los gastos en compras y los legados testamentarios, que en muchos casos son testimonios únicos para conocer con todo detalle la evolución del archivo, y que tienen el mejor complemento en los recientes trabajos de catalogación de los fondos bibliófilos y musicales de esta catedral.

\section{LOS ESPACIOS CLAUSTRALES}

Tras la construcción de la catedral románica de Burgo de Osma a comienzos del siglo XII por el obispo Pedro de Bituris, años más tarde, en 1232, en esta ocasión bajo los auspicios de don Juan Domínguez Medina, da comienzo la obra de un nuevo edificio en estilo gótico de tres naves y cabecera con cinco absidiolos ${ }^{1}$. Con el paso de los años se van incorporando retablos, capillas, rejas y en 1515 un nuevo claustro costeado por Alonso Enríquez y bajo la dirección arquitectónica de Juan y Pedro de la Piedra y de Francisco Mogica². En él estaban las dependencias en las que habitaba el clero bajo la autoridad del prior, varias capillas, estancias y, como en tantas catedrales, un pozo que abastecía de agua. Además, fue lugar de culto, de formación, de custodia de libros y espacio de tránsito para las procesiones de la Octava del Corpus y Jueves Santo ${ }^{3}$.

En la actualidad, nada más acceder al claustro, encontramos en la panda este, dos arcadas y un espacio que sirvió de sala capitular o capilla de Sancti Spiritus, iniciada hacia 1200 en un estilo silense, que mantuvo este cometido hasta el siglo $\mathrm{XV}^{4}$. Desde ella se entra a la capilla del Tesoro, edificada en el siglo XIV, de planta cuadrada sobre columna central, que servía al mismo tiempo

1 José Arranz Arranz, La catedral de Burgo de Osma (Soria). Guía turística, Burlada, 1981, pp. 29 y 37.

2 María José Redondo Cantera, Nuevas noticias sobre fulio Sormano, en Archivo español de Arte, t. 71, 281 (1998), p. 42; y Luis CERVERA VERA, Mecenas y artifices en la arquitectura renacentista, en Principe de Viana, 52 (1991), p. 14.

3 Eduardo Carrero Santamaría, Las oficinas capitulares de la catedral de Ávila, en Cuadernos Abulenses, 28 (1999), p. 146, e ID., La topografía claustral de las catedrales del Burgo de Osma, Sigüenza y Tarragona en el contexto del Tardorrománico Hispano, en La cabecera de la catedral calceatense y el Tardorrománico hispano: Simposio sobre la Cabecera Calceatense y el Tardorrománico Hispano. Santo Domingo de la Calzada, 2000, pp. 389-417.

4 Joaquín YarZa LuaCES, Nuevas esculturas románicas en la catedral de Burgo de Osma, en Boletín del Seminario de Estudios de Arte y Arqueología, XXXIV-XXXV (1969), pp. 217-229. 


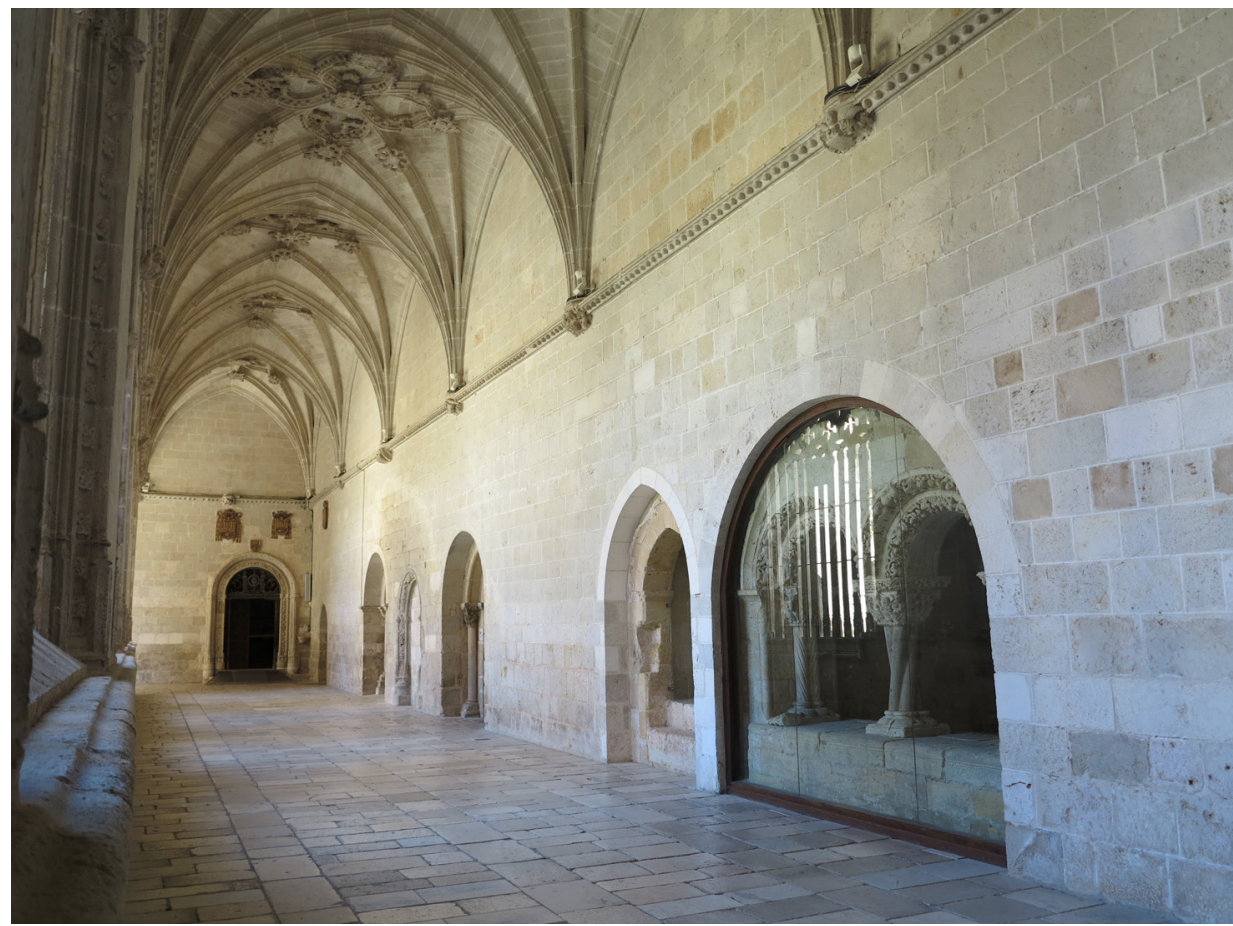

Figura 1. Panda este con la arcada de la antigua sala capitular, acceso primitivo al piso superior, la capilla de los Treintanarios, puerta de la biblioteca, salida a la calle del Pozo, capilla de la Virgen de las Angustias y Capilla de la Concepción (fot. José Ignacio Palacios).

de sacristía mayor, capilla de las reliquias y sitio para la custodia de las alhajas de plata y joyas ${ }^{5}$.

De nuevo en el claustro, estaba la estrecha Cámara de los Treintanarios mandada construir por don Pedro Montoya (1454-1475), y que desde 1527 servirá de contaduría y en ocasiones de librería. En su interior había un altar con el privilegio de decir misas petitorias por el alma de un difunto, tal y como había establecido en sus cláusulas testamentarias. Con el paso de los años quedará

5 Vicente NúÑEz MarquÉs, Guía de la S.I Catedral del Burgo de Osma y Breve historia del Obispado de Burgo de Osma, Madrid, 1949, p. 12; Fernando CHUECA GOITIA, La arquitectura religiosa en el siglo XVIII y las obras del Burgo de Osma, en Archivo de Arte Español, 22 (1949), p. 298, y Eduardo CARRERO SANTAMARÍA, La sacristía catedralicia en los reinos hispanos. Evolución topográfica y tipo arquitectónico, en Liño. Revista Anual de Historia del Arte, 11 (2005), pp. 53-54. La capilla del Tesoro desempeñó tal función hasta la edificación en la girola de la nueva sacristía, diseñada por Juan de Villanueva e inaugurada en 1775. 
únicamente con el cometido de sacristía de capellanes ${ }^{6}$. En la planta superior se hallaban inicialmente los dormitorios del cabildo y luego pasó a desempeñar las funciones de biblioteca, archivo, oficinas y sala capitular, a los que se accedía desde el claustro por un vano apuntado y una estrecha escalera, que es cerrada en el siglo XVI y en su lugar se abre un nuevo acceso al lado de la puerta de la Cámara de los Treintanarios. Nada más pasar la salida a la calle del Pozo, por la que entraba el obispo a la catedral o salía al exterior hacia el palacio episcopal, está la capilla que inicialmente se llamó de San Agustín y posteriormente de la Virgen de los Ángeles, fundada en 1292, con dos altares, uno con la pintura de la Virgen de los Ángeles del maestro de Osma, que hoy se halla en los museos catedralicios, y el otro dedicado a San Crispín y San Crispiniano, que se encuentra desaparecido ${ }^{7}$.

En el extremo norte se abrió hacia 1520 la capilla de Nuestra Señora de la Concepción y contigua a ella la funeraria de Santa Catalina, que con el paso de los años quedó como almacén de la fábrica, fundada por el arcediano Pedro de García de Barreda ${ }^{8}$. Seguidamente, aparece la magnífica puerta plateresca de la librería con las armas del obispo Alonso Enríquez, que también funcionó como sala de reunión capitular durante el verano 9 . Al final de este lado norte estaba el refectorio y junto a él la puerta que da acceso al Paño de San Miguel o cementerio de la villa. Toda el ala oeste cambió varias veces de uso, sirviendo la parte inferior unas veces como cárcel eclesiástica y otras como archivo de papeles y lugar de ensayo de la capilla de música en la capilla, en concreto en la capilla de San Bartolomé. A su vez, la planta superior dio cobijo a las celdas conventuales y más tarde pasó a ser las casas de los dependientes catedralicios ${ }^{10}$. Por último, en la esquina de la panda oeste con la sur, Pedro Jordán edificó en 1525 la capilla de San Joaquín y Santa Ana, destinada junto a otra estancia para los racioneros de la catedral. Por último y a su lado, había otra pequeña destinada a dar culto a San Isidro Labrador, que como la anterior sufrió serios daños tras el hundimiento de la torre ${ }^{11}$.

6 ARChivo Catedral bURgo de OSMa (=ACBO), Libros de Cuenta de Fábrica (=LCF), t. 1511, f. 150v, y Fernando MARTíneZ GIL, Muerte y sociedad en la España de los Austrias, Cuenca, 2000, pp. 541-543.

7 Teófilo Portillo Capilla, Instituciones del Obispado de Osma, Soria, 1985, pp. 153 y 166.

8 María Dolores CAmpos SánCHEZ-Bordona, Estudios de casos. La librería de la catedral de Burgo de Osma, en Librerías catedralicias: un espacio del saber en la Edad Media y Moderna, León, 2013, p. 203; y María Dolores CAMPos SánCHEZ-Bordona y María Dolores TeIJeIRA Pablos, Declive y desaparición de las librerías catedralicias castellanas en la Edad Moderna, en José Javier VÉLEZ CHAURRI, Pedro Luis ECHEVERría GoÑI y Felicitas MARTíneZ SALINAS (eds.), Estudios de Historia del Arte en memoria de la profesora Micaela Portilla, Vitoria-Gasteiz, 2008, pp. 305-314.

9 Juan Loperráez Corvalán, Descripción histórica del Obispado de Osma, t. 1, Madrid, 1788, pp. 69-70.

10 Teófilo PORTILlo CaPILla, Instituciones... [cit. nº. 7], pp. 143-153 y 165-166.

11 Juan Loperráez Corvalán, Descripción..., t. 1 [cit. nº. 9], p. 70. 


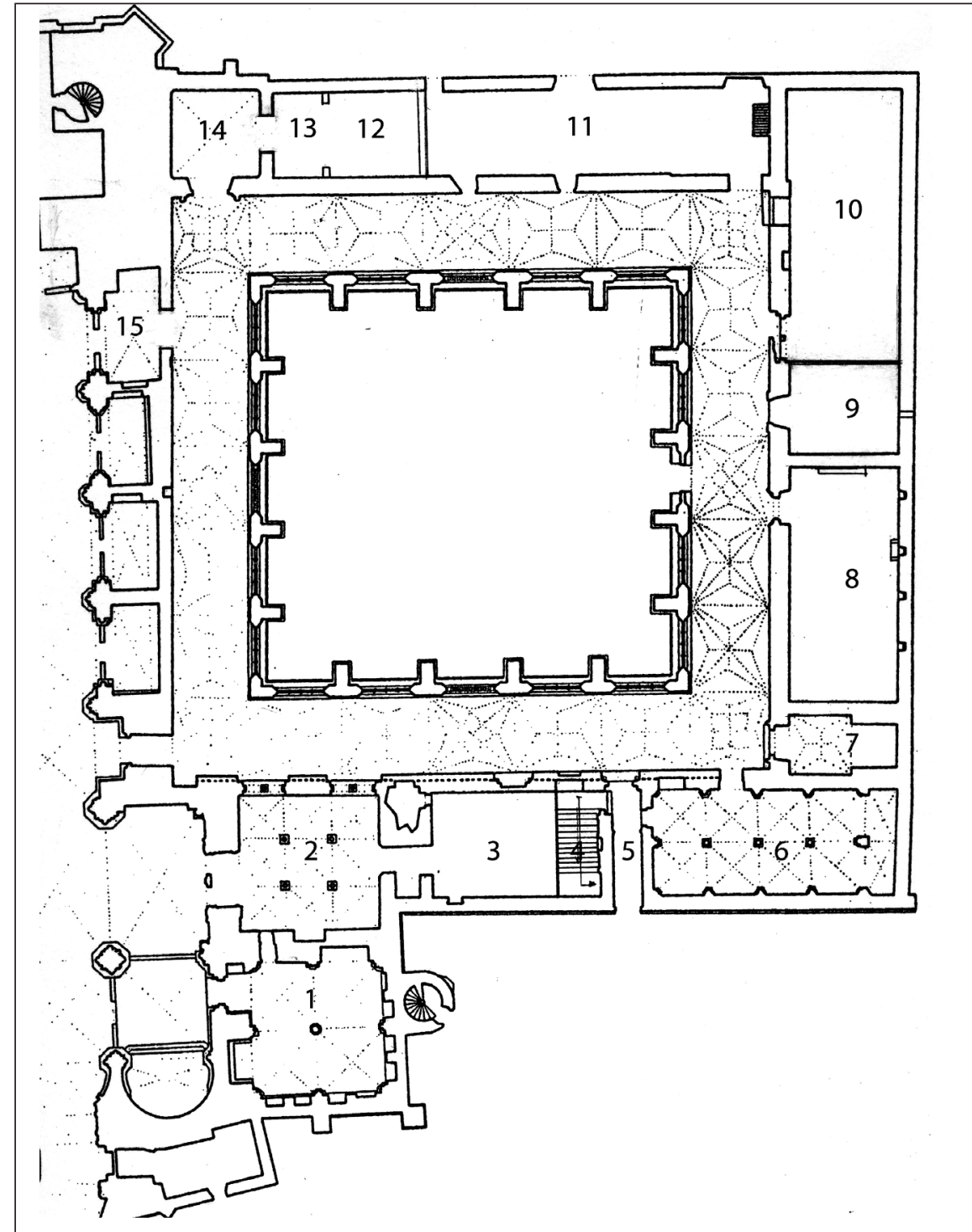

Figura 2. Plano del claustro de la catedral de Burgo de Osma. 1: Capilla del Tesoro y antigua sacristía; 2: Sala Capitular del Sancti Spiritus; 3: Capilla de los Treintanarios, antigua Contaduría y archivo de música; 4: Subida al Archivo y Sala Capitular desde el s. XVI; 5: Salida a la calle del Pozo; 6: Capilla de San Agustín o de la Virgen de los Ángeles; 7: Capilla de Nuestra Señora de la Concepción; 8: Capilla de Santa Catalina; 9: Librería y Sala del capítulo en verano; 10: Antiguo Refectorio; 11: Paño de San Miguel; 12: Capilla de San Bartolomé; 13: Vestuario de Capellanes; 14: Capilla de San Joaquín y Santa Ana (luego de la Inmaculada); y 15: Capilla de San Isidro (Fundación Santa María la Real. Centro de Estudios del Románico. (c) María del Carmen Fernández Laso. Enciclopedia del Románico en Castilla y León, Soria, vol. 1, y elaboración propia). 


\section{SENTIDO Y FUNCIÓN DE LOS ARCHIVOS CATEDRALICIOS}

Todo archivo es un depósito de una ingente cantidad de material documental y bibliófilo, dentro de un espacio físico que se verá sometido por sucesivos controles y orientado a la conservación de los instrumentos del conocimiento. La génesis de las librerías catedralicias está íntimamente unida a la creación de las escuelas catedralicias en dependencias claustrales, con amplitud suficiente para admitir nuevos volúmenes procedentes de sucesivas donaciones y adquisiciones ${ }^{12}$. Desde del cuarto concilio Lateranense de 1216 y de Valladolid de 1322, aparte de los sínodos de León de 1303, Palencia de 1346, y años después los de Aranda de Duero, de 1473, y Sevilla, de 1478, ambos impulsados por los Reyes Católicos, todos insisten en el aprendizaje y lectura del latín como elemento esencial en la formación del clero $^{13}$. Fruto de estas reformas, en la década de 1490 y principios de 1500, fueron creadas los nuevos recintos librarios en la mayoría de las catedrales siguiendo un modelo francés: en Salamanca en la antigua capilla de Santa Catalina ${ }^{14}$, en Ávila ${ }^{15}$, León ${ }^{16}$, Santiago ${ }^{17}$, Ciudad Rodrigo, Segovia, Zamora y Osma ubicadas en un espacio habilitado con tal fin en una de las alas del claustro ${ }^{18}$.

La ordenación y custodia de la biblioteca y archivo ha sido una constante en la vida de cualquier catedral. Pero será hasta el siglo pasado cuando la Iglesia

12 Lo mismo sucede en la catedral de Sevilla. Ver Pedro Rubio Merino, Archivo de la Santa Metropolitana y Patriarcal Iglesia Catedral de Sevilla. Inventario general, Sevilla, 1987, p. 13.

13 Bernardino LlorCa, Ricardo García Villoslada y Francisco Javier Montalbán, Historia de la Iglesia Católica, t. 3, Madrid, 1960, pp. 599-600, y María Dolores SÁNCHEZ-BordONA, Las bibliotecas catedralicias en Castilla y León. El ejemplo de Ciudad Rodrigo, en E. AZOFRA (ed.), La Catedral de Ciudad Rodrigo a través de los siglos. Visiones y revisiones, Salamanca, 2006, p. 503.

14 Fernando Chueca Goitia, La catedral nueva de Salamanca. Historia documental de su construcción, Salamanca, 1951, p. 214.

15 Ernesto Carrero SANTAMaría, Las oficinas capitulares... [cit. nº. 3], pp. 151-156.

16 ID., La canónica de la catedral de León. Respuestas góticas a una estructura secular, en Joaquín YARZA Luaces, María Victoria HerráEz OrTEga y Gerardo Boto VARELA (coords.), Congreso Internacional La Catedral de León en la Edad Media, León, 2003, p. 244.

17 ID., La capilla de los Arzobispos, el tesoro y la torre de don Gómez Manrique en la Catedral de Santiago de Compostela, en Anuario del Departamento de Historia y Teoría del Arte (U.A.M.), IX-X (1997-1998), pp. 35-41, e ID., Las catedrales de Galicia durante la Edad Media. Claustros y entorno urbano, A Coruña, 2005, pp. 49-50 y 310.

18 María Dolores SÁnchez-Bordona y María Dolores Teijeira Pablos, Declive... [ver nº. 8], pp. 3-4 y 6; María Dolores SÁNCHEZ-Bordona, Las bibliotecas catedralicias... [cit. nº. 13], p. 513; y María Dolores Campos Sánchez-Bordona y María Dolores Teijeira Pablos, Génesis y evolución de los espacios librarios de las catedrales de Castilla y León, en Memoria Ecclesiae, XXXIII (2009), pp. 28-29 y 33 . 
dé un tratamiento jurídico a sus archivos, regulados primero por el Concordato de 1953, y posteriormente por el acuerdo de la Santa Sede con el Estado Español de 1979 y el Código de Derecho Canónico de $1983^{19}$, aparte de la creación en 1997 por la Conferencia Episcopal Española de la Asociación de Archiveros de la Iglesia, con la misión de difundir la cultura católica conservada en sus $\operatorname{archivos}^{20}$.

\section{HISTORIA DEL ARCHIVO Y BIBLIOTECA}

Entre los importantes fondos medievales destaca el códice n. $^{\circ} 1$, titulado Comentarios al Apocalipsis de Beato de Liébana del año 1086, que pudo pertenecer al antiguo convento de San Miguel, anterior a la restauración de la sede episcopal, y en la sección documental la Carta homenaje para recibir el castillo de Alcozar del año 1154, junto a varios censos, donaciones y privilegios pertenecientes a la segunda mitad del siglo $\mathrm{XII}^{21}$. Una de las primeras referencias testamentarias es el legado del obispo Ximénez de Rada (c. 1170-1247)22, compuesto por varios salterios, sermones, epístolas, libros de canto toledano, historia, astrología, gramática y cuestiones de teología. Precisamente, de esta etapa se ha conservado varios ejemplares de libros litúrgicos y el códice Ciceronis de inventione rethorica libri II ${ }^{23}$. A su vez, en la década de los años setenta del siglo XV el obispo humanista Montoya contribuyó sensiblemente en la mejora del archivo capitular con la importante donación de incunables, libros de coro y códices, que estaban guardados en arcas y encadenados a pupitres con estanterías ${ }^{24}$, hecho que se repite por entonces en

19 Fernando CARbajo y Vanessa JimÉnEz CASCÓn, El tratamiento de la documentación musical, en Pedro GómeZ GONZÁLEZ (coord.), El archivo de los sonidos, Salamanca, 2008, pp. 285-286.

20 Agustín Vivas Moreno y María Guadalupe PÉREZ OrTIZ, La información histórica en los archivos eclesiásticos: principales series documentales para la investigación, en Documentación de las Ciencias de la Información, 34 (2011), pp. 443-444.

21 Timoteo Rojo Orcajo, Catálogo descriptivo de los códices que se conservan en la Santa Iglesia Catedral de Burgo de Osma, Madrid, 1929, pp. 9 y 17-21; y José Vicente Frías BALSA, Carta homenaje por recibir el castillo de Alcozar, Concordia entre el obispo de Osma, Burgos y Sigüenza sobre los nuevos términos de la diócesis, y Donación de la villa de Soto de Suso al obispo don fuan y a sus sucesores y Privilegio de Sancho III, en La Ciudad de Seis Pisos, Torrejón de Ardoz, 1997, pp. 132, 146 y 147-148.

22 Manuel DíAZ Y DíAZ, Notas de bibliotecas en Castilla en el siglo XIII, en Livre et lecture en Espagne sous l'Ancien Régime: Colloque de la Casa Velásquez, París, 1981, p. 11.

23 Timoteo Rojo Orcajo, Catálogo descriptivo... [cit. no. 21], pp. 56-60; Teófilo PorTiLlo CaPILLA, Instituciones... [cit. nº. 7], pp. 226-235; y Susana GUIJARRO GONZÁLEZ, Maestros, escuelas y libros. El universo cultural de las catedrales en la Castilla medieval, Madrid, 2004, p. 125.

24 Juan Loperráez Corvalán, Descripción..., t. 1 [cit. nº. 11], p. 366. 
muchas catedrales (Salamanca ${ }^{25}$, Santiago ${ }^{26}$, Sevilla ${ }^{27}$ y Ávila ${ }^{28}$ ) y que hasta hace unos años aún se podía contemplar en la catedral de Palencia ${ }^{29}$.

La forma de vida agustiniana fue abandonada tardíamente en esta catedral con respecto a otros cabildos, en concreto en 1536, por lo que a partir de ese instante muchas partes del claustro tuvieron que adaptarse a nuevas necesidades, al mismo tiempo que los clérigos -al igual que sucede en Ávila- ocuparon casas ubicadas en las inmediaciones del templo ${ }^{30}$. Todavía la documentación estaba guardada ordenadamente en arcas con cajones de madera junto a los papales de la contabilidad, que siempre era el conjunto que ocupaba un mayor volumen, lo cual obligó a buscar un nuevo emplazamiento para el archivo en el piso superior de la contaduría ${ }^{31}$. A renglón seguido, también se suceden importantes donaciones por vía testamentaria y por compras realizadas por los prelados Pedro Álvarez De Acosta (1539-1563) 32; Sebastián Pérez (1582-1593), que repartió su legado entre Osma y el colegio de Oviedo ${ }^{33}$; Alonso Clemente de Aróstegui, quien donó de la Biblia Políglota Complutense de Cisneros y recuperó varios libros del obispo Honorato Juan ${ }^{34}$, así como por el doctoral Cristóbal Pérez ${ }^{35}$. Es entonces el momento oportuno para ordenar el «despacho», hacer recuentos, vender libros en desuso, colocar correctamente los fondos y reclamar los códices cedidos en 1568 al Escorial y que nunca regresaron ${ }^{36}$.

25 Florencio Marcos RodrígueZ, La antigua biblioteca de la catedral de Salamanca, en Hispania Sacra, 14 (1961), pp. 5, y 24.

26 Eduardo Carrero Santamaría, La Capilla de los Arzobispos... [cit. nº 17], p. 45.

27 Mari Carmen Álvarez MárqueZ, El mundo del libro en la Iglesia Catedral de Sevilla en el siglo XVI, Sevilla, 1992, p. 24.

28 Susana GuIjARro GonZÁleZ, Maestros... [cit. nº. 22], p. 135.

29 José Manuel RUIZ ASENCIO, Conferencia inaugural «Mis experiencias personales en los archivos eclesiásticos», II Curso Aprender a Historiar, Instituto Universitario de Historia Simancas, Universidad de Valladolid, 26 octubre de 2017.

30 Teófilo Portillo Capilla, La congregación de canónigos de San Agustín en la catedral de Santa María de Osma, en XX Siglos, 33 (1997), p. 79; y Eduardo CARRERO SANTAMARÍA. Las oficinas capitulares... [cit. $\mathrm{n}^{\circ} .3$ ], p. 131.

31 ACBO, Libro de Actas Capitulares (=LAC), t. 1, f. 250 v.

32 Juan Loperráez Corvalán, Descripción..., t. 1 [cit. nº. 9], p. 419 y t. II, p. 70. Ver también el caso de Salamanca, en Florencio Marcos RodríGUEZ, La antigua biblioteca... [cit. nº. 24], p. 284.

33 Juan Loperráez Corvalán, Descripción..., t. 1 [cit. nº. 9], p. 460; y Bernabé BARTOLOMÉ MARTíneZ, Antiguas escuelas de la catedral de Burgo de Osma, en Celtiberia, 29 (1979), pp. 260-263.

34 Juan Loperráez Corvalán, Descripción..., t. 1 [cit. nº. 9], p. 574.

35 María Dolores Campos SánCheZ-Bordona, Estudios de casos... [cit. no . 8], p. 206.

36 ACBO, LAC, t. 7, ff. 178 y 219, LCF, t. 1578-1667, s.f., y Timoteo ROJO ORCAJO, Catálogo descriptivo de los códices que se conservan en la Santa Iglesia Catedral de Burgo de Osma, en Boletín de la Real Academia de la Historia, 94 (1929), pp. 664-665. 
EVOLUCIÓN, ESPACIOS Y CONTENIDOS DEL ARCHIVO Y DE LA LIBRERÍA MUSICAL...

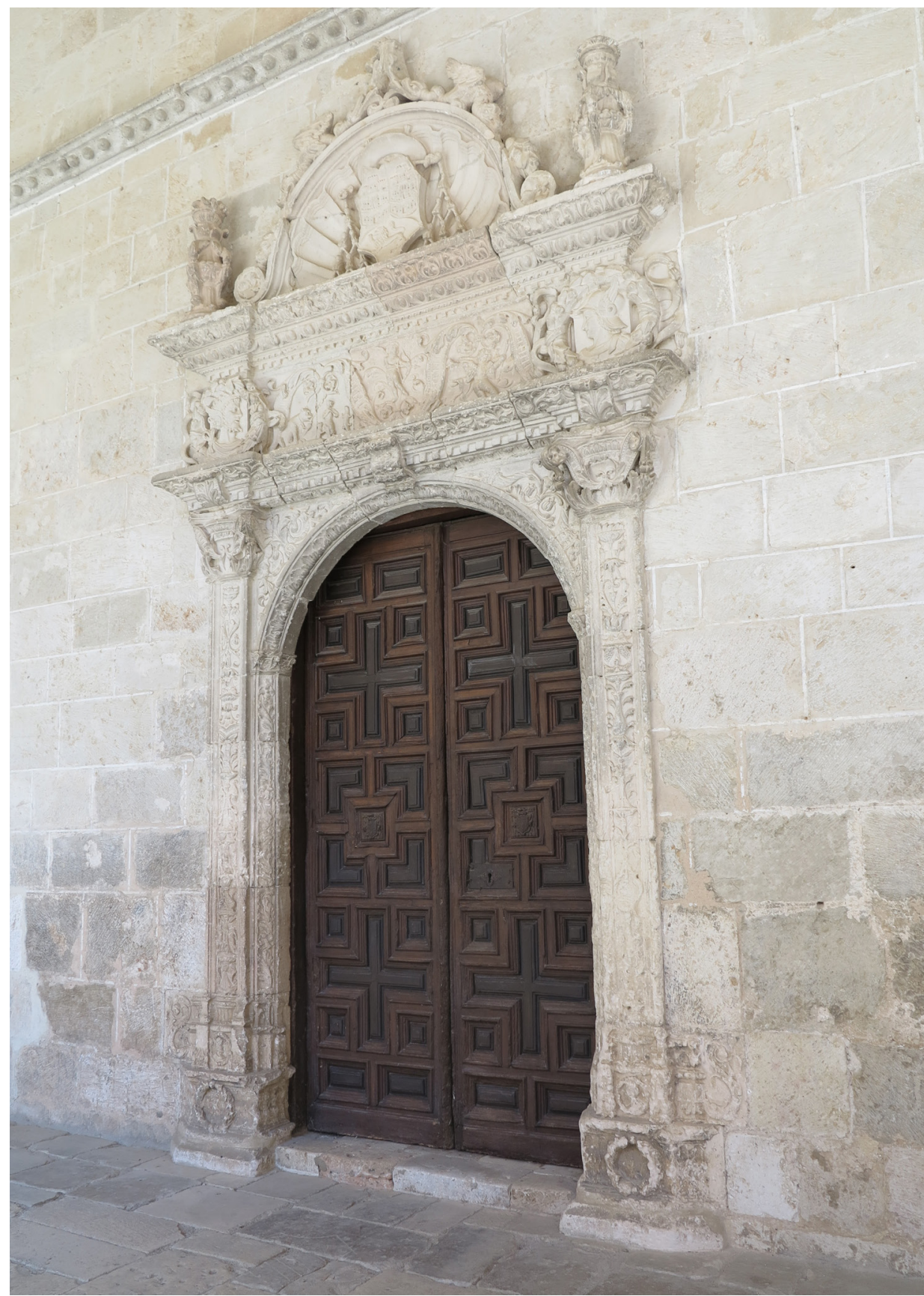

Figura 3. Portada a la antigua librería levantada por el obispo Alonso Enríquez (c. 1525) (fot. José lgnacio Palacios). 
A partir de 1627, hubo la necesidad de acometer reformas y comprar mobiliario nuevo ${ }^{37}$. Con el paso de los años la librería seguía resultando insana y llena de humedades, motivo por el que en 1704 la trasladan a la sala superior del lado este del claustro, al mismo tiempo que mandan hacer unos nuevos estantes, comprar vidrieras e instalar un bufete grande y dos escritorios comprados a la Almoneda, más un marco para la copia de Rafael de la Transfiguración que engalanaba la estancia ${ }^{38}$. Los libros y legajos son reorganizados y clasificados en 1713 y en cada estante colocan unas cartelas para facilitar su localización ${ }^{39}$. Al lado de esta estancia quedaba otra abovedada que en algún momento tuvo la función de sala capitular -justo encima de la capilla de la Virgen de los Ángeles- y junto a esta otra pequeña estancia a modo de almacén, llamada aún en 1743 la «sala vieja» y que años más tarde pasará a ser la contaduría ${ }^{40}$. No hay nuevas noticias hasta el 28 de marzo de 1754, cuando los monjes carmelitas de la villa intentan comprar «dos juegos» impresos en Roma por el precio de 30 doblones $^{41}$. Cuatro años después deciden reorganizar todo este espacio, y para ello deciden instalar la biblioteca en el lugar que ocupaba la antigua sala capitular, ya que era más segura al estar contigua a la casa del canónigo Vera, según las trazas dadas por Antonio Serrano ${ }^{42}$. $\mathrm{Al}$ año siguiente inician el proceso de recuperación de fondos en poder de varios capitulares y estrenan veinte armarios, que son los mismos que han llegado hasta nosotros, fabricados en madera de nogal y estructurados en cuatro baldas ${ }^{43}$. En 1761 añaden a la librería parte de los fondos del colegio de Santa Catalina ${ }^{44}$, en 1767 mandan hacer nuevos estantes ${ }^{45}$, en 1784 re-catalogan toda la biblioteca ${ }^{46}$.

37 Millán BRavo Lozano, La biblioteca capitular (B. C.) de Palencia: historia, valoración y significado, vol. 4, Palencia, 1987, pp. 57-58, y АСBO. $L A C$, t. 12 , f. 88 y t. 16, ff. 18 y 19 v.

38 ACBO, LCF, t. 1668-1711, s.f.; y José ARRANZ ARRANZ, Visita a algunas piezas y lugares de la catedral de Burgo de Osma en que vivió Santo Domingo, en Luis Vicente DíAZ-MARTín y Cándido ÁNIZ IRIARTE (coords.), Santo Domingo de Caleruega. IV Fornadas de Estudios Medievales, Salamanca, 1996 , pp. 123 y $283-294$.

39 ACBO, $L C F$, t. $1712-1745$, s.f.

40 ACBO, $L A C$, t. 35 , f. 173 v.

41 ACBO, $L A C$, t. 37, cabildo 28 marzo de 1754, s.f.

42 ACBO, $L A C$, t. 38, ff. 233 v-234 y 257 v., y LCF, t. 1668, s.f. Para subir al archivo desde el claustro era necesario abrir una puerta que poseía un sistema muy curioso de apertura. Al final de la escalera se hallaba un cuadro de San Cristóbal, y la escalera terminaba justo en la puerta de la biblioteca, quedando el archivo como un espacio diáfano. Con la aparición de unas arcadas románicas en el claustro en los años setenta, incomprensiblemente se suprime este acceso.

43 ACBO, $L A C$, t. 38 , ff. 327 v. -328.

44 ACBO, $L C F$, t. $1746-1775$, f. 205 v.

45 Ibid., f. 288.

46 ACBO, $L A C$, t. 46 , ff. $97-97$ v. y 139 v. 
Por último, cabe reseñar el azote de varios incendios acaecidos durante 1505, 1703, 1769 y 1774, siendo los más devastadores el de 1668 y 1812, en los que hubo pérdidas irreparables, incluso para la música ${ }^{47}$.

\section{EL CONTENIDO DEL ARCHIVO-BIBLIOTECA CAPITULAR EN LA ACTUALIDAD}

El archivo fue estudiado primeramente por Zacarías García Villada en 1914, a continuación, en 1929 por Timoteo Rojo Orcajo ${ }^{48}$, y fue inventariado por Florentino Zamora en los años cuarenta del siglo pasado y más recientemente por la Junta de Castilla y León ${ }^{49}$. Presidía la sala un altar con pequeñas alacenas para el papeleo relativo a las obras pías y al hospital de San Agustín. A su vez, de las paredes colgaban un apostolario y varios lienzos. En la actualidad, la entrada se realiza por la capilla de San Pedro de Osma, con una primera gran sala, llamada Sala del Cabildo, mientras la biblioteca mantiene intacto el espacio con estanterías y tres armarios acristalados. Al fondo, a la izquierda, se accede a la antigua contaduría y en ella se ha practicado una puerta para el nuevo archivo ignífugo, situado sobre la que fuera capilla de Santa Catalina, estructurado en las siguientes secciones: Obispalía, Mesa común, Cámara, Canonjías, Obispo y Cabildo, Medias annatas, Estatutos y Autos capitulares, Subsidios, Diezmos y Cruzada, Informaciones, Hospital y Arca de misericordia, Memorias, Aniversarios y Palafox ${ }^{50}$. Sobresalen los 224 códices de los siglos XII al XIV, 400 pergaminos (bulas, censos, papeles de cámara, privilegios y diezmos), 77 incunables $^{51}, 12$ gruesos volúmenes del pro-

47 ACBO, LCF, t. 1668, s.f. y Sinforiano CANTOLLA Y DE LAS POZAS, Índice de asuntos tratados por el cabildo catedral de El Burgo de Osma (Soria). Actas capitulares desde el año 1513, Burgo de Osma, 1929 , p. 49.

48 Zacarías GarCía VILlaDa, Metodología y Crítica histórica, Barcelona, 1921, p. 157; Timoteo Rojo OrCAJO, Catálogo descriptivo... [cit. nº. 22], pp. 5-6; y Juan B. VILlar, Francisco VíCTOR y María Jesús VILLAR (trans. y estudio), Catálogo de la biblioteca romana del Cardenal Luis Belluga, Murcia, 2009, pp. 334, 273, 221, 207, 198 y 108. Estos autores hacen referencia, entre otros, a las siguientes obras del archivo burgense, Paulus Antonius Tarsia, Arius Pinelus, Barnardus Lamy, Bernardus Bogdanovitz o Juan de Santa María.

49 José María Martí Bonet (dir.), Guía de los Archivos de la Iglesia en España, Barcelona, 2001, pp. 539-540.

50 Ibid., p. 539.

51 Mar Campos Souto, El Memorial de «Virtudes» de Alonso Cartagena, en Actas del VI Congreso Internacional de la Asociación Hispánica de Literatura Medieval, t. 1, Madrid 1997, p. 424, y Aida PORTILLA, El saber medicinal en Castilla (siglos XIII-XIV): la biblioteca de la catedral de Sigüenza, en Medievalismo, 24 (2014), p. 336. 


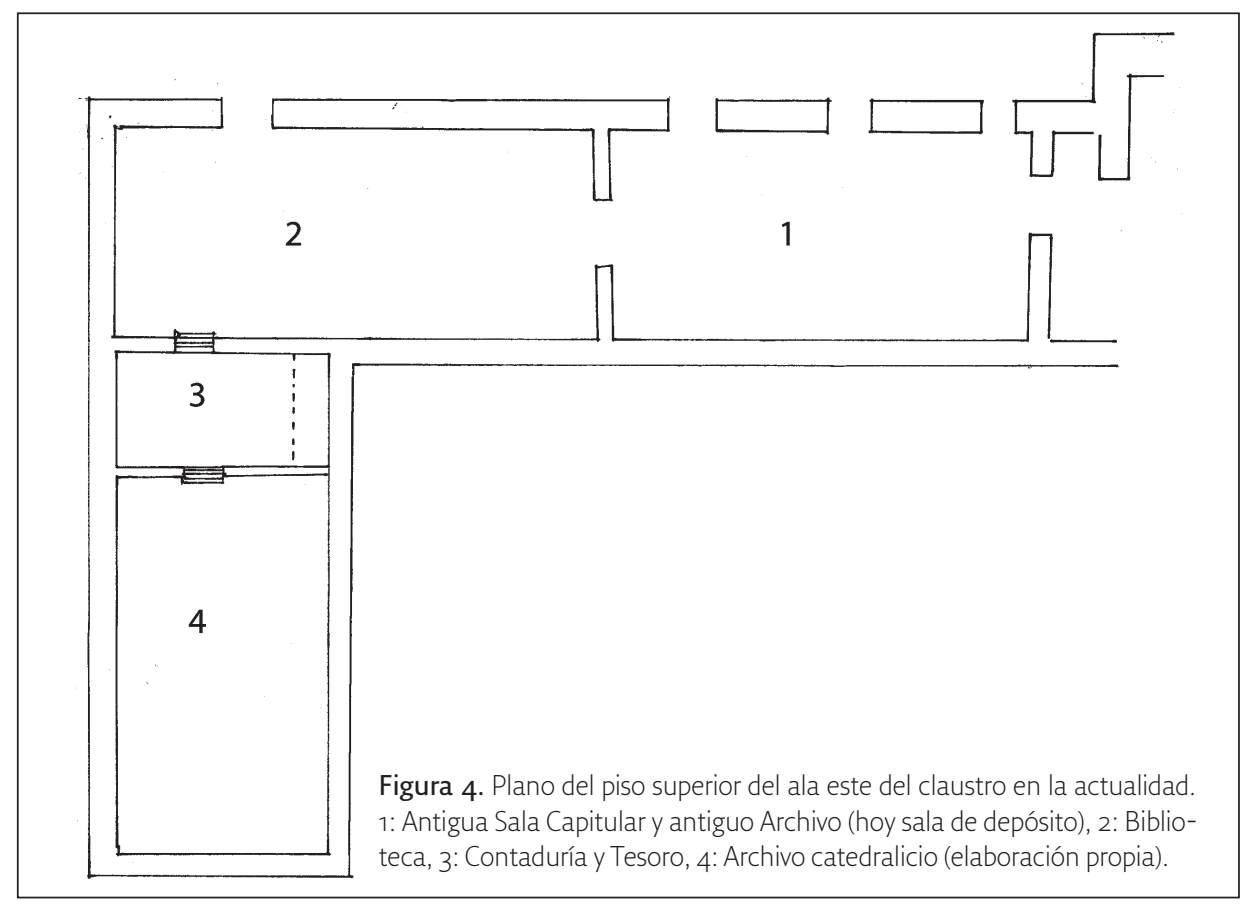

ceso de beatificación de Palafox y varias obras impresas suyas y un importante número de libros, algunos piezas únicas, y una interesante colección de legajos sobre expedientes de linaje y cartas $^{52}$.

\section{LA LIBRERÍA DE MÚSICA}

En la catedral de Osma la librería de música estaba formada por dos entidades diferentes, por un lado, los libros de canto llano, y por otro, los libros de canto polifónico y la música a papeles. Los primeros estaban depositados y repartidos, según el uso que se les diera, entre el coro, alguna capilla próxima y el vestuario de capellanes ${ }^{53}$, bajo la responsabilidad del sochantre y el gobierno del

52 Gregorio Bartolomé Martínez, Acta Palafoxiana. Viaje de iniciación a los fondos de archivos y bibliotecas sobre don Fuan de Palafox y Mendoza, en Ricardo FERNÁNDEZ García (coord.), Palafox: Iglesia, Cultura y Estado en el siglo XVII, Pamplona, 2001, pp. 38-39.

53 Pedro José Gómez GonZÁleZ y Raúl ViCENTE BAZ, Guía del Archivo y Biblioteca de la Catedral de Salamanca, Salamanca, 2007, pp. 47-48. En Salamanca la música estaba depositada en unos 
cabildo. En cambio, la librería de canto de órgano, que también era propiedad de la fábrica de la catedral e incumbencia del cabildo, estuvo depositada primero en arcones situados a los pies del facistol del coro, para, más tarde, pasar a las dependencias del $\operatorname{archivo~}^{54}$. A su vez, las partituras y partichelas estaban al cuidado del maestro de capilla, repartidas entre la capilla de ensayos de San Bartolomé y su casa, pero a partir de 1779 los libros de canto de órgano así como los demás papeles del archivo musical quedan confinados en la capilla de la Santa Cruz en un armario con cajones, bajo llave y custodia del maestro de capilla ${ }^{55}$. Por último, hace unas décadas todo quedó integrado en el archivo capitular ${ }^{56}$.

\subsection{Inventarios}

La música española debe agradecer a las catedrales la generosa y amplia producción y así como el haber salvaguardado el variado y rico patrimonio musical manuscrito e impreso ${ }^{57}$. En cada una de ellas, los fondos musicales existentes muestran a la vez contenidos con personalidad propia y elementos comunes, que sirven en su conjunto para estudiar la historia de la música religiosa y la historia musical de estas instituciones, sus autores, géneros musicales y las técnicas compositivas.

A lo largo del siglo XVI la mayoría de catedrales españolas realizan inventarios de sus fondos, siendo una de las pioneras Toledo ${ }^{58}$, a la que siguen Salaman$\mathrm{ca}^{59}$, Sevilla ${ }^{60}$ y Tarazona ${ }^{61}$. En Osma tenemos constancia escrita de una primera

cajones de una capilla, y los cantorales en unos estantes debajo del órgano de la epístola y desde 1843 al lado de la Contaduría.

54 ACBO, $L C F$, t. 1511 , f. 191 v. y t. 1578 , f. v. 125 v., y $L A C$, t. 6 , f. 347 v.

55 ACBO, $L A C$, t. 45, f. 302 v., y t. 1886, f. 317. En una ocasión pasaron eventualmente al cuarto de incensarios de la sacristía mayor.

56 ACOS, $L A C$, t. 10, ff. 217 v., y 242 y 244 v. La capilla de San Bartolomé cumplió el cometido de lugar de ensayos de la capilla de música hasta el año 1614.

57 José Vicente GONZÁLEZ VALLE, Spanish Ecclesiastical Archives: Musical documentation, en Fontes Artis Musicae, 45/ 1 (january-march 1989), p. 39.

58 François RaYNaUd, La Polyphonie Tolédane et son milieu des premiers temoignages aux environs de 1600, Paris, 1996, pp. 370-371.

59 Florencio Marcos RodríGUeZ, La antigua biblioteca... [cit. nº. 24], p. 281.

$60 \mathrm{M}^{\mathrm{a}}$ del Carmen Álvarez Márquez, El Mundo del libro en la Iglesia Catedral de Sevilla en el siglo XVI, Sevilla, 1992.

61 Pedro CALAHORRa, Los fondos musicales en el siglo XVI de la Catedral de Tarazana. I. Inventarios, en Nassarre. Revista Aragonesa de Musicología, VIII-2 (1992), pp. 9-56; y Julián RUIZ IZQUIERDO, José Antonio Mosquera y Justo Sevillano, Biblioteca de la Iglesia Catedral de Tarazona. Catálogo de libros manuscritos, incunables y de música, Zaragoza, 1984. 
indexación en 1574, realizada por dos infantes mayores ${ }^{62}$, a la que sigue otras de los libros de canto llano y de polifonía, respectivamente, en $1590^{63}$ y $1596^{64}$. Pero a partir de 1664 el cabildo inaugura la costumbre de que el maestro de capilla nada más tomar posesión de esta ración y como parte de sus obligaciones confeccione los listados oportunos de todos los libros y papeles de música existentes en la catedral ${ }^{65}$. De ahí que, los inventarios se suceden en 1708, 1718, 1780, 1791, 1832 y $1853^{66}$. Esta práctica se mantiene hasta nuestros días junto a la recuperación de todo el material que estuviera disperso ${ }^{67}$.

\subsection{Los libros de canto de órgano: producción propia y adquisiciones}

A mediados del siglo XVI las dos principales catedrales de la corona de Castilla afrontan una renovación del material polifónico para adaptase al nuevo estilo compositivo que cubriera todas las necesidades litúrgicas según las normas de Trento. Para ello, el maestro de capilla oxomense Baltasar Ruiz compone varias misas al mismo tiempo que adquieren, con unos gastos elevados, composiciones de otros maestros. Así, empiezan a circular en varias oleadas por todas las catedrales españolas obras impresas y manuscritas a partir de los centros difusores de Sevilla, Ciudad Rodrigo, Madrid y Zaragoza. La llegada de la primera generación de compositores en Burgo de Osma se inicia con Cristóbal de Morales con el sistema de la «donación remunerada ${ }^{68}$. Ya durante la segunda mitad del siglo XVI, Francisco Guerrero tiene aún con más calado que el anterior y deja una fuerte impronta en todo el territorio peninsular al correr de forma paralela a las reformas tridentinas ${ }^{69}$.

62 ACBO, $L A C$, t. 4 , ff. 86 v. y 112 v.

63 ACBO, $L C F$, t. 1511 , f. 86 v., y $L A C$, t. 6 , f. 331 v.

64 ACBO, Inventario de las cosas del Thesoro de la Santa Iglesia de Osma, 1596-1628, ff. 89-91 v. y José Ignacio PALACIOS SANZ, «De Re musicae». Nuevas aportaciones musicales en la catedral de El Burgo de Osma, en Revista de Soria, 16 (1997), p. 69.

65 ACBO, $L A C$, t. 16, f. 445 v.

66 ACBO, $L A C$, t. 23 , f. $196 ; L C F$, t. 1712 , s.f.; $L A C$, t. 46 , f. 90 , y $L A C$, t. 1791 , ff. 142 v. -143 у $L A C$, t. 1831 , s.f.

${ }^{67}$ Juan RuIZ JiméneZ, La Librería de Canto de Órgano. Creación y pervivencia del repertorio del Renacimiento en la actividad de la Catedral de Sevilla, Granada, 2007, p. 12.

68 ACBO, LCF, t. 1511, f. 182 v.; José LÓPEZ-CALO, La música en las catedrales españolas, Madrid, 2012, pp. 340-341; y Juan RUIZ JimÉNEZ, La Librería de canto... [cit. nº. 65], pp. 143-144. En todos los casos estudiados es el propio compositor quien ofrece al cabildo la obra impresa, para, posteriormente, ser evaluada por el maestro de capilla, y tras su dictamen el cabildo se encarga de los aspectos económicos para su compra.

69 Herminio GONZÁLEZ BARRIONUEVO, Francisco Guerrero (1528-1599). Vida y obra. La música en la catedral de Sevilla a finales del siglo XVI, Sevilla, 2000, pp. 375-376. 
EVOLUCIÓN, ESPACIOS Y CONTENIDOS DEL ARCHIVO Y DE LA LIBRERÍA MUSICAL...

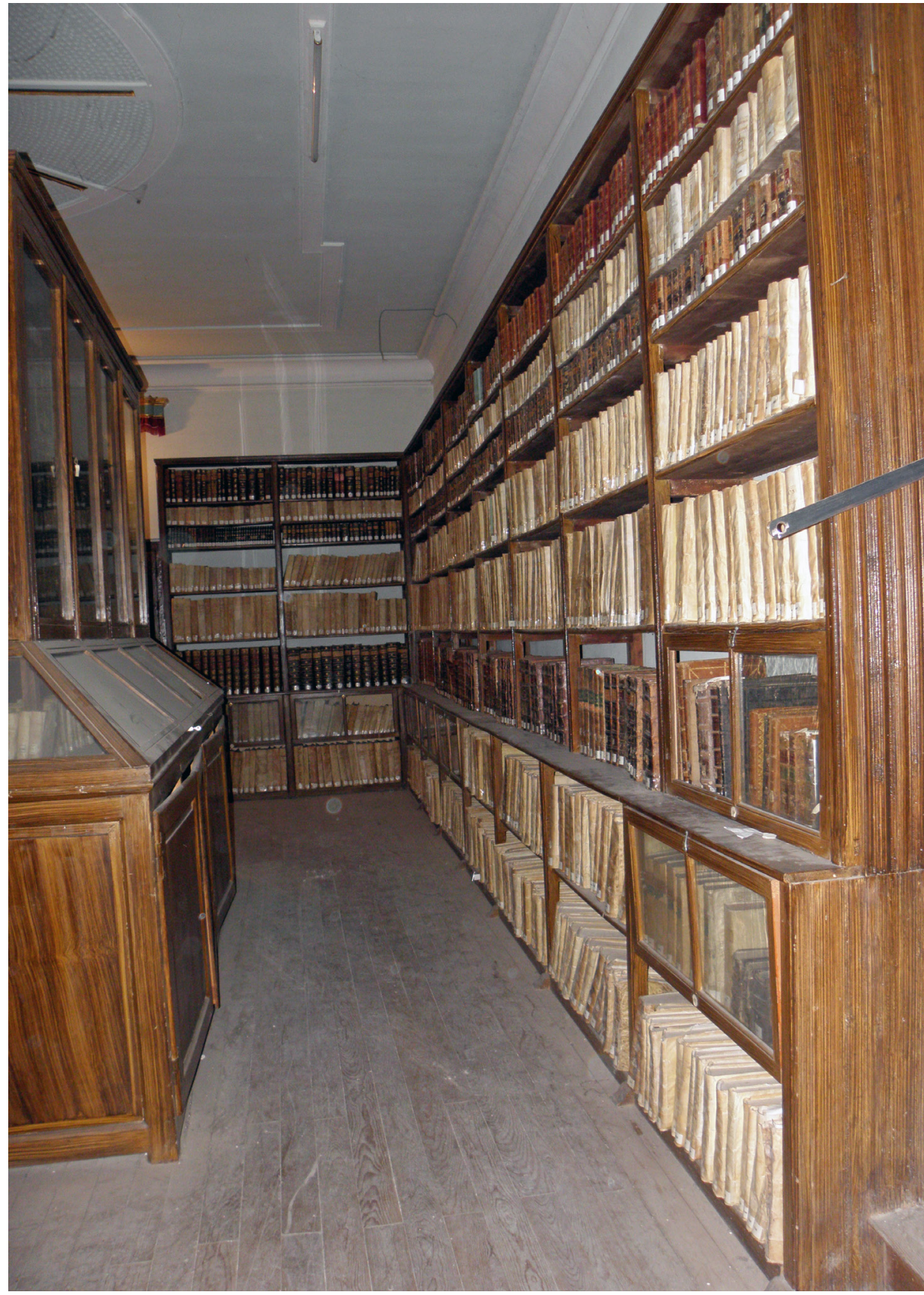

Figura 5. Archivo de la catedral de Burgo de Osma: vista interior de la Biblioteca (fot. José Ignacio Palacios). 
Él envía desde Sevilla Burgo de Osma en 1567 un «libro de madera» ${ }^{70}$, que pudiera ser el Liber primus Missarum, y casi veinte años después, en 1585, el cabildo compra en Roma los libretes de un juego de motetes suyos muy populares, los Cantus Motect $a^{71}$. Además, él fue el que introdujo de forma generalizada el repertorio de varios compositores foráneos, como es el caso de Josquin, Carpentas, Crecquillon, Ockeghem o Janequin ${ }^{72}$. Tampoco falta en ésta y en el resto de catedrales la música italiana que culmina con la llegada de misas y motetes de Palestrina, al ser Guerrero el responsable de la recepción de su $\mathrm{obra}^{73}$. Algunos de estos volúmenes, como dato curioso, estaban cosidos a mano en cuadernillos a punta de espiga y venían sin encuadernar, por lo que posteriormente eran recubiertos con tapas de terciopelo rojo o amarillo que daban nombre al libro ${ }^{74}$.

Los géneros más utilizados por los polifonistas inmersos en el espíritu de la Contrarreforma fueron los ciclos de himnos, misas y las antífonas marianas, interpretados generalmente con la tradicional fórmula alternatim. Tienen como principal protagonista a Juan Navarro ya que su producción tuvo una amplia difusión gracias a las ediciones romanas de 1584 (ésta a cargo de su sobrino Fernando Navarro Salazar) y al libro Psalmi, Hymni ac Magníficat totius anni de 1590, editado con la ayuda de su amigo personal, el soriano Francisco Soto de Langa $^{75}$. También contó con su apoyo Tomás Luis de Victoria, siguiendo así lo

70 ACBO, LCF, t. 1511, f. 319 v.

71 ACBO, LCF, t. 1578 , ff. 78 y 79 v., y 259 v.

72 ACBO, Inventario de las cosas del Thesoro... [cit. $\mathrm{n}^{\circ}$. 62], s.f.; Robert STEVEnSON, fosquin in the music of Spain and Portugal, en Edward E. LOWINSKY y Bonnie J. BLACKBURN (eds.), Fosquin des Prez. Proceedings of the International Fosquin Festival-Conference, Londres, 1976, pp. 217-246; Emilio Ros FÁBREGAS, Libros de música en las bibliotecas españolas del siglo XVI (I), en Pliegos de Bibliofilia, 15 (2001), p. 48; y Pedro Jiménez CaVallé, Los inventarios de música de la Catedral de faén en los siglos XVI y XVII, en Senda de los Huertos, 17 (1990), p. 68. La catedral de Granada fue la primera en tener un libro de misas de canto de órgano de Josquin en 1523 y posteriormente la de Jaén en 1548 .

73 José LópeZ-Calo, Palestrina e la contrariforma musicale in Spagna, en Giancarlo RosTiROLLa y Lino BIANCHI (eds.), Atti del II Convegno Internazionale di Studi: Palestrina e la sua presenza nella musica e nella cultura europea dal suo tempo ad oggi, Palestrina, 1991, pp. 239-250.

74 Juan RuIZ JimÉNEZ, Recepción y pervivencia de la obra de Victoria en las instituciones de la Corona de Castillas, en Alfonso DE VICENTE y Pilar TOMÁs (dirs.), Tomás Luis de Victoria y la cultura musical en la España de Felipe III, Madrid, 2012, pp. 310-311 y 346. Cuando en 1593 recibe el cabildo de Burgo de Osma el libro de las Missae quattor, señala que ya venía encuadernado en «becerro colorado».

75 ACBO, LAC, t. 6, ff. 319 v., 323 y 362; LCF, t. 1578, f. 138; Asunción GÓMEZ PINTOR, Voz fuan Navarro, en Emilio CASARES RODICIO (dir.), Diccionario de la música española e hispanoamericana, t. 7, Madrid, 2000, pp. 992-994; y José LópeZ-Calo, Voz Osma, El Burgo de, en Diccionario de la música española e hispanoamericana, t. 8, Madrid, 2001, p. 271. 
pasos de su maestro Navarro, llegando a ser uno de los compositores de mayor calado por la pervivencia de su obra a lo largo de los siglos ${ }^{76}$. La circulación de libros de Victoria fue abundante por todo el territorio peninsular, incluso por las catedrales de la franja mediterránea, siendo Tarazona la que conserva el conjunto más importante de obras victorianas ${ }^{77}$. Así, cuando en 1576 envía los Motecta al cabildo hispalense desde Roma, hace otro tanto con varios cabildos con su Liber primus qui missas, psalmos, magnificat ${ }^{78}$. Y a partir de entonces se suceden varias recepciones por toda la geografía peninsular, como sucede en Ávila en 1583 a $1593^{79}$, Cuenca en $1584^{80}$, Las Palmas y Osma en $1584^{81}$, Sigüenza en $1588^{82}$, y Cuenca y Osma en 1590 (en ésta, gracias a la intermediación del antiguo organista de la catedral Diego del Castillo, llegan nuevos volúmenes junto a unos motetes y el libro Psalmi, Hymni ac Magníficat totius anni de Juan Navarro) ${ }^{83}$; Guadix en $1592^{84}$, León en 1593, Las Palmas en 1594, de nuevo Jaén y Salamanca en 1601 con un libro de misas y Málaga en $1602^{85}$. Al mismo tiempo, se realizaron copias manuscritas de la producción de maestros locales y de estos libros impresos, como es el caso del libro de canto de órgano compilado por el maestro de capilla Sebastián López de Velasco en 1609 con obras suyas, de Morales y Guerrero, o el legado que dona Jerónimo de León a la catedral de Valladolid en el que se encuentran varias obras de Victoria. A veces también su uso prolongado y la pérdida de continuidad en su interpretación dio lugar a que se arrinconaran ${ }^{86}$.

76 Juan RUIZ JimÉNEZ, Recepción y pervivencia... [cit. nº.73], p. 313.

77 Alfonso DE VICENTE, Libros y obras de Tomás Luis de Victoria (y otros) en Aragón, Ávila, 2016, p. 8.

78 Ferrol HernándeZ HernáNDEZ, Tomás Luis de Victoria «el abulense», Ávila, 1960, pp. 113-114 y 147-150; y Pedro Jiménez CaVallé, Documentario musical de la catedral de faén II. Documentos de Secretaría, Granada, 2010, p. 6.

79 Ana María SABE ANDreU, Tomás Luis de Victoria, pasión por la música, Ávila, 2008, pp. 167-168.

80 Juan RuIZ JimÉNEZ, Recepción y pervivencia... [cit. nº. 73], p. 346.

81 Sinforiano Cantolla y DE LAS POZAS, Índice de los asuntos... [ver. n ${ }^{\circ} .45$ ], pp. 58-59.

82 Javier SuÁreZ Pajares, La música en la catedral de Sigüenza, vol. II, Madrid, 1998, p. 4.

83 ACBO, $L A C$, t. 6, ff. 319 v., 323 y 362, y LCF, t. 1578, f. 138.

84 Juan RUIZ JIMÉNEZ, Difusión del repertorio de los maestros de capilla de Granada en el siglo XVI, en Revista de Musicología (RdeM), 20/1 (1997), p. 177.

85 Alfonso DE ViCENTE, Tomás Luis de Victoria: cartas (1582-1606), Madrid, 2008, pp. 54, 58, 68, 84 y 90.

86 ACBO. LAC, t. 9, f. 272; Cristina URChUEGUíA-SCHÖLZEL, El códice $n r .2$ del archivo de la catedral de Segovia. Inventario comentado «Addendum» al Catálogo de D. Fosé López-Calo, en Nassarre. Revista Aragonesa de Musicología, 15/1-2 (1999), p. 14; y Soterraña AgUiRRE RinCón, The formation o fan exceptional library: Early printed music book at Valladolid, en Early Music, 37/3 (aug. 2009), p. 383. 


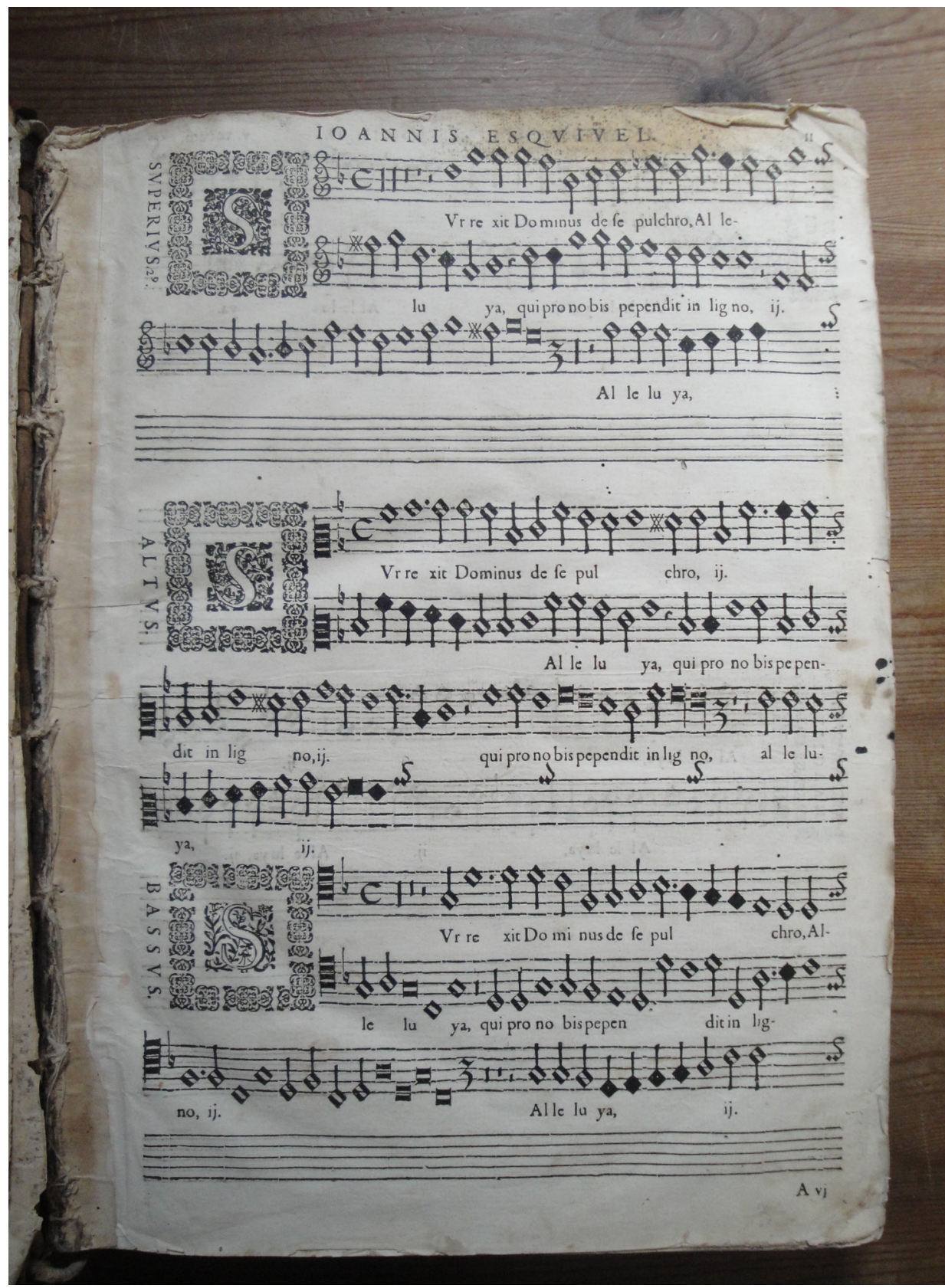

Figura 6. Libro de Polifonía nº. 2, Libro de Misas, motetes y salmos, Juan Esquivel de Barahona, 1608 (fot. José Ignacio Palacios). 
Durante el siglo XVII se abandona progresivamente la tipología de libro polifónico de facistol por la música en papeles sueltos ${ }^{87}$, ya que asistimos a una renovación estilística en las composiciones en romance, en parte gracias al movimiento rotativo en el préstamo de las letras y a la dispersión de obras que viajaban con su autor a los nuevos destinos (existen colecciones de villancicos compuestos en Osma en los archivos de las catedrales de Ávila, Palencia, Salamanca, Segovia, Valladolid y en la Biblioteca Nacional de Madrid) ${ }^{88}$. La librería musical sigue sin un espacio específico, pero los libros impresos aumentan considerablemente en un espacio corto de tiempo -de 1608 a 1613 - con las incorporaciones de Sebastián de Vivanco y los tres volúmenes que envía de Juan Esquivel de Barahona desde Ciudad Rodrigo publicados en Salamanca por la imprenta del flamenco Artus Taberniel, que junto a la familia Junti fueron los que dieron un gran impulso en España la impresión de música vocal ${ }^{89}$. También en 1620 reciben en esta catedral, Ávila y Burgos ${ }^{90}$ el volumen compuesto por Sebastián Aguilera de Heredia, titulado Canticum Beatissimae Virginis Deiparae

87 Lola De LA TORRE, Documentos sobre la música en la catedral de Las Palmas (1601-1605), en Museo Canario, 50 (1995), pp. 403-406, y Ramón PELINSKI, La polifonía vocal española del siglo XVII y sus formas de escribirla, en Anuario Musical, 24 (1969), pp. 164-166.

88 José López-Calo, La Música en la Catedral de Valladolid. Catálogo del Archivo de Música, vol. I, Valladolid, 2007, pp. 327-328, y vol. II, pp. 66-67, y 79-82; Josefa MONTERO GARCÍA (coord.), Catálogo de los fondos musicales del archivo catedral de Salamanca, Salamanca, 2011, pp. 1049, 1069 y 1092; José LóPEZ-CALO, La música en la catedral de Palencia, t. 2, Palencia, 1980, pp. 28-29 y 158-159, y José LóPEZ-CALO, Catálogo del archivo de Música de la Catedral de Ávila, Santiago de Compostela, 1978, pp. 176-177, y 135-138. Los autores que tiene composiciones en estos archivos son Miguel Gómez Camargo, Tomás Micieces, Adrián González de Gámiz, Francisco Pascual, Mateo Villavieja, Francisco Vicente y Bernardo Pérez. Para las obras de la Biblioteca Nacional ver Mari Cristina GuILlÉN BERMEjO y Isabel RUIZ DE ELvira SERRA (coord.), Catálogo de villancicos y oratorios en la Biblioteca Nacional: siglos XVIII-XIX, Madrid, 1990, pp. 332-334. Signaturas VE/1305/135, VE/1305/136, VE/1305/137 y VE/1305/138. Además, aquí encontramos el Oratorio alegórico y moral al nacimiento de Jesu-Christo que se han de cantar en la catedral de Osma que escribió el maestro Pérez (R/34981/37).

89 ACBO, $L A C$, t. 9 (1605), f. 240 v. y 334; t. 11, f. 147 y LCF, t. 1578, f. 259 v.; Ian FENLON, Artus Taberniel. Music printig and the book trade in Renaissance Salamanca, en Ian Fenlon y Tess Knighton (eds.), Early Music Printing and Publishing in the Iberian World, Kassel, 2006, p. 129, y Francisco RODILla LEÓN, Estudio, transcripción e interpretación de los motetes de fuan Esquivel de Barahona (ca. 1560-ca.1624), en Actas del VI Congreso de la Sociedad Española de Musicología, en RdeM, 28/2 (2015), p. 1547. El impreso de Esquivel de Barahona titulado Missarum rinde un explícito homenaje a Guerrero con tres misas parodias, como así hizo Victoria con un motete de este compositor hispalense. Además, se encuentran más ejemplares de esta edición en las catedrales de Coria, Badajoz, Plasencia, y Oviedo.

90 Ramos AHIJADO, La catedral de Ávila como institución, Salamanca, 2011, p. 64, y https://www.fundacioncajacirculo.es/AHCB_D.php?cod=39297\&nombre=Libro (consulta 19 marzo de 2016). 
Mariae, que pudo ser muy utilizado en las grandes solemnidades, aunque hoy está desaparecido, así como el Libro de Misas, motetes, salmos, Magníficat y otras cosas tocantes al culto divino, adquirido en 1629 a Sebastián López de Velasco y del que existen copias en numerosas catedrales ${ }^{91}$. Las últimas compras se enmarcan en el magisterio de Tomás Micieces en el escritorio de Las Descalzas de Madrid junto a las donaciones de varios cantorales polifónicos de Juan García de Salazar ${ }^{92}$.

Abre el siglo XVIII la carta del organista de la Real Capilla, José de Torres, dando cuenta de la publicación de su libro de facistol que no es comprado tras el pertinente informe del maestro Villavieja ${ }^{93}$; más tarde copian el libro de facistol Missarum liber de Palestrina, y en 1774 fray Manuel de la Purificación realiza el meticuloso trabajo en papel de tipo imperial con los himnos de Juan Navarro $^{94}$. El archivo de música ocupará desde 1765 un nuevo armario en la angosta contaduría claustral ${ }^{95}$, pero pronto, en 1773 , tiene que ser ampliada al comprar al librero Cifuentes varios antifonarios e himnarios, además de pasar todo este material a un armario custodiado por el maestro de capilla ${ }^{96}$. También merecen una mención especial el grupo de tratados teóricos impresos de Francisco Santa María Dialectos músicos (1788) y el de Bernardo Pérez, editado en 1800, Instituciones elementales de la Música, de los que no hay ni rastro en este $\operatorname{archivo}^{97}$.

91 ACBO, LCF, t. 1578, f. 305; Carta de Sebastián López, Armario 7, tabla baja, legajo sin numerar, s.f., y $L A C$, t. 12 , f. 142 v. En 1628 se trabaja en un nuevo inventario para reunir y ordenar el material viejo junto al nuevo.

92 ACBO, $L A C$, t. 20, f. 199-199v.; t. 15, f. 183, y t. 22.1, f. 48; Antonio EZQUERRO EsTEBAN, $V i$ llancicos policorales aragoneses del siglo XVII, Barcelona, 2000, p. 12, y Alejandro IGLESIAS, En torno al barroco musical español: el oficio y la misa de difuntos de Juan García de Salazar, Salamanca, 1989, pp. 26-27, y 33-34.

93 ACBO, $L A C$, t. 22.2 , ff. 296 v y 297 v.

94 ACBO, $L A C$, t. 44, ff. 15 v., 40 y 46, y LCF, t. 1780, data 1782-1783, s.f.; Guy BouRLIGUEUX, Voz López Navarro, Casiano, en Emilio CASARES RODICIO (dir.), en Diccionario de la música española e bispanoamericana, vol. 6, Madrid 2000, p. 1031; Emilio ROS-FÁBREGAS, Libros de polifonía en la Catedral de Pamplona, en Príncipe de Viana, 67/238 (2001), pp. 341 y 368, y José Ignacio PaLACios SANZ, Libro de salmos e himnos, en La Ciudad de Seis Pisos. Las Edades del Hombre, Torrejón de Ardoz, 1997, pp. 323-324.

95 ACBO, $L A C$, t. 40 , ff. 408 v.-409.

96 ACBO, $L C F$, t. 1746 , f. 366 , y $L A C$, t. 44 , f. 15 v.

97 Francisco José LEÓN TeLlO, Introducción a la estética y a la técnica española de la música en el siglo XVIII, en RdeM, IV/1 (1981), pp. 115 y 120-124, y José Ignacio PALACIOS SANZ, Tres siglos de música en la catedral de El Burgo de Osma, Soria, 1991, pp. 549-559. 


\begin{tabular}{|c|c|c|}
\hline Autor & $\begin{array}{l}\text { Año de } \\
\text { compra }\end{array}$ & Título \\
\hline Francisco Guerreo & 1567 & Liber primus Missarum \\
\hline Francisco Guerreo & 1585 & Cantus Motecta \\
\hline Juan Navarro & 1584 & Liber missarum \\
\hline Juan Navarro & 1590 & Psalmi, Hymni ac Magníficat totius anni \\
\hline Tomás Luis de Victoria & 1582 & Liber primus qui missas, psalmos, magnificat \\
\hline Tomás Luis de Victoria & 1584 & Hymno totius anni \\
\hline Tomás Luis de Victoria & 1590 & Motecta festorum totius anni \\
\hline Sebastián de Vivanco & 1608 & Liber magnificarum \\
\hline Juan Esquivel de Barahona & 1608 & $\begin{array}{l}\text { Missarum. Ioannis Esquivelis in alma ecclesia } \\
\text { civitatensi portionarii, et cantorum praefecti, liber } \\
\text { primus }\end{array}$ \\
\hline Juan Esquivel de Barahona & 1609 & $\begin{array}{l}\text { Motecta festorum et dominicarum cum communi } \\
\text { sanctorum IV, V, VI, et VIII vocibus concinenda }\end{array}$ \\
\hline Juan Esquivel de Barahona & 1613 & $\begin{array}{l}\text { Psalmorum, hymnorum, magnificarum, et Mariae } \\
\text { quatuor antiphonarum de tempore, nec non et missarum } \\
\text { Tomus secundus }\end{array}$ \\
\hline Sebastián Aguilera de Heredia & 1620 & Canticum Beatissimae Virginis Deiparae Mariae \\
\hline Sebastián López de Velasco & 1629 & $\begin{array}{l}\text { Libro de Misas, motetes, salmos, Magnificat y otras } \\
\text { cosas tocantes al culto divino }\end{array}$ \\
\hline Juan García de Salazar & 1692 & Libro de Magníficats \\
\hline Giovanni P. L. de Palestrina & 1728 & Liber Missarum \\
\hline \multirow[t]{2}{*}{ Juan Navarro (copia) } & 1774 & Psalmi, Hymni ac Magnificat totius anni \\
\hline & 1805 & Libros de misas y vísperas \\
\hline Perosi & 1904 & Varias misas \\
\hline M. Hilarión Eslava & 1911 & Misas \\
\hline Resmer & 1925 & Misa \\
\hline Lorenzo Perosi & 1925 & Missa in honorem beati Caroli de Perosi \\
\hline Autores del s. XX & $1940 / 60$ & Misas, motetes y otras obras. \\
\hline
\end{tabular}

Figura 7. Adquisiciones y donaciones de obras de polifonía, s. XVI-XX (elaboración propia) 
Durante el siglo XIX se producen más copias que compras, a la par que se recuperaban obras de Eslava y del difunto maestro Pérez ${ }^{98}$. No obstante, en el capítulo de nuevas incorporaciones tenemos varios libros de misas y vísperas traídos de Zaragoza en $1805^{99}$ y un segundo grupo en 1861 siguiendo las indicaciones dadas por el propio Eslava ${ }^{100}$. A su vez los ciclos himnódicos de Victoria y Navarro continúan en uso durante esta centuria de forma estable gracias a las copias en papel.

La aplicación del Motu Proprio se produce en Burgo de Osma en 1904, con la recepción de misas de Perosi, además del Liber usualis. Como continuación de este proceso, los estatutos establecen que el maestro tiene la obligación de depositar una obra anual a estrenar, que era interpretada en las solemnidades más importantes por la capilla de música de la catedral y la Schola cantorum del Seminario ${ }^{101}$. El archivo musical sigue creciendo durante el magisterio de Francisco Solanas con obras de compositores contemporáneos (Grassi o Botazzo) y de los siglos XVI y XVIII (Viadana y Ardanaz) ${ }^{102}$. Hacia mediados de siglo adquieren las ediciones del Seminario de Vitoria y obras procedentes de las revistas Música Sacro Hispana y Tesoro Sacro-Musical, aparte de un abundante repertorio de editoriales nacionales y extranjeras.

\subsection{Los libros de canto llano}

Son más conocidos con el nombre de cantorales y contenían la música en canto llano para la liturgia de las horas y las misas, escritos tras un largo proceso de elaboración del pergamino, y encuadernados con tapas de madera y herrajes, alcanzando pesos aproximados entre los 30 y los $40 \mathrm{~kg}$. En la actualidad han sido objeto de estudio en las catedrales de Ávila ${ }^{103}$, Cádiz ${ }^{104}$, Córdoba ${ }^{105}$, Granada $^{106}$,

98 ACBO, LAC, t. 1831-1832, cabildo de 11 y 30 de junio; 1 y 22 de agosto, 3 de septiembre y 3 de diciembre de 1832, s.f.; t. 1920, f. 185 v.; Libro de Acuerdos Espirituales (=LAE), t. 1845, cabildo de 10 enero de 1853, s.f., y José Ignacio PaLACIOS SANZ, Tres siglos de música... [ver. no . 96], p. 120.

99 ACBO, $L A C$, t. $1803-1805$, s.f.

100 ACBO, $L A C$, t. $1861-1862$, s.f.

101 ACBO, $L A C$, t. 1911, ff. 3 v., 50, 90, 134 v., 163, y 190 v.

102 ACBO, $L A C$, t. 1920 , ff. 178 v. y 185 v.

${ }^{103}$ Lynette M. F. BosCH, Los manuscritos abulenses de Fuan de Carrión, en Archivo Español de Arte, LXIV/253 (1991), pp. 55-64.

104 José Antonio GARCía Luján, Los libros corales de la catedral de Cádiz, en Historia, Instituciones, Documentos, 32 (2005), pp. 151-153.

105 Javier LARA LARA, El canto llano en la catedral de Córdoba. Los libros corales de la Misa, Granada, 2004.

106 Sylvie Denise GaRCía DE LA CALle, El Canto llano en la Catedral de Granada y en La Capilla Real de Granada: Repertorio medido, tesis doctoral, Universidad de Granada, 2017, pp. 198-226. 
Segovia ${ }^{107}$, Sevilla ${ }^{108}$, y Tarazona ${ }^{109}$, y si bien algunos de estos trabajos solo se han centrado en el apartado de las miniaturas.

Por razones codicológicas y textuales establecemos cinco etapas para su clasificación en la catedral de Burgo de Osma ${ }^{110}$. El primer grupo coincide con los episcopados de Pedro de Montoya y Alfonso de Ulloa Fonseca; es decir, entre 1470 a 1505 . Están relacionados con el escritorio de Espeja y el iluminador conocido como «Maestro de Osma». Recogen los cantos para el Oficio divino para todo el calendario litúrgico, desde Adviento a Navidad (n. ${ }^{\circ} 1$ al 22), y el $\operatorname{Kyrial}\left(\text { n. }^{\circ} 25\right)^{111}$. La primera referencia documental corresponde al 15 de enero de 1514, acerca de la confección por Manuel Garrido de varios leccionarios, cantorales y dominicales ${ }^{112}$. Junto a él figura la actividad de la familia Salazar, que también trabajó para la catedral de Segovia ${ }^{113}$; el impresor de origen vallisoletano, Diego Fernández de Córdoba, que tuvo varios encargos del obispo Álvarez de Acosta, aparte de una serie de cantorales y varias encuadernaciones en cuero ${ }^{114}$; Pedro de la Flor, y varios artistas locales, como el escritor Cristóbal Rodríguez ${ }^{115}$.

La segunda etapa coincide con la aprobación del Decretum super indice librorum, catechismo, breviario et missali, publicados mediante sendas bulas de 1568 y 1570. El nuevo rezo va incorporándose paulatinamente y su aplicación no será una tarea fácil en la catedral oxomense. Desde entonces va a ser constante el procedimiento de adicción de páginas, modificación y raspado de ciertos pasajes para eliminar melismas en las vocalizaciones finales, virgas y ligaduras. En este

${ }^{107}$ Hilario SanZ SanZ, XXV Exposición de Arte Antiguo. Cantorales o libros de coro, en Estudios Segovianos, 71-72 (1972), pp. 209-226.

$108 M^{\mathrm{a}}$. Rosario DomíngueZ BeníTEZ, Los libros corales de la catedral de Sevilla, siglos XVII, XVII y XIX, en La Catedral de Sevilla, Sevilla, 1984; y Rosario MARCHENA HidalgO, Las miniaturas de los libros de coro de la catedral de Sevilla: el siglo XVI, Sevilla, 1998.

109 María Pilar FALCÓN PÉREZ, Estudio artístico de los manuscritos iluminados de la Catedral de Tarazona (Análisis y Catalogación), Zaragoza, 1996.

110 Javier LARA LARA, El canto llano en la catedral de Córdoba... [ver nº. 104], p. 56; y Santiago RUIZ TORRES, La monodia litúrgica entre los siglos XV y XIX. Tradición, transmisión y praxis musical a través del estudio de los libros de coro de la catedral de Segovia, tesis doctoral, Universidad Complutense de Madrid, 2013, p. 45.

111 Anna Muntada y Juan Carlos ATIEnZa, Cantorales del Monasterio de San ferónimo de Espeja, Soria, 2003, p. 51.

112 ACBO, LCF, t. 1511 , ff. $40 \mathrm{v}-41$.

113 Santiago RUIZ TORRES, La monodia... [ver $\mathrm{n}^{\circ}$. 109], p. 99.

114 Ángeles Domínguez Llorente, Pasionario, en La Ciudad de los Seis Pisos... [ver no. 92], p. 307, y ACBO, $L C F$, t. 1511, ff. 249 y 259.

115 Ibid., ff. 182, y 192-192 v. 


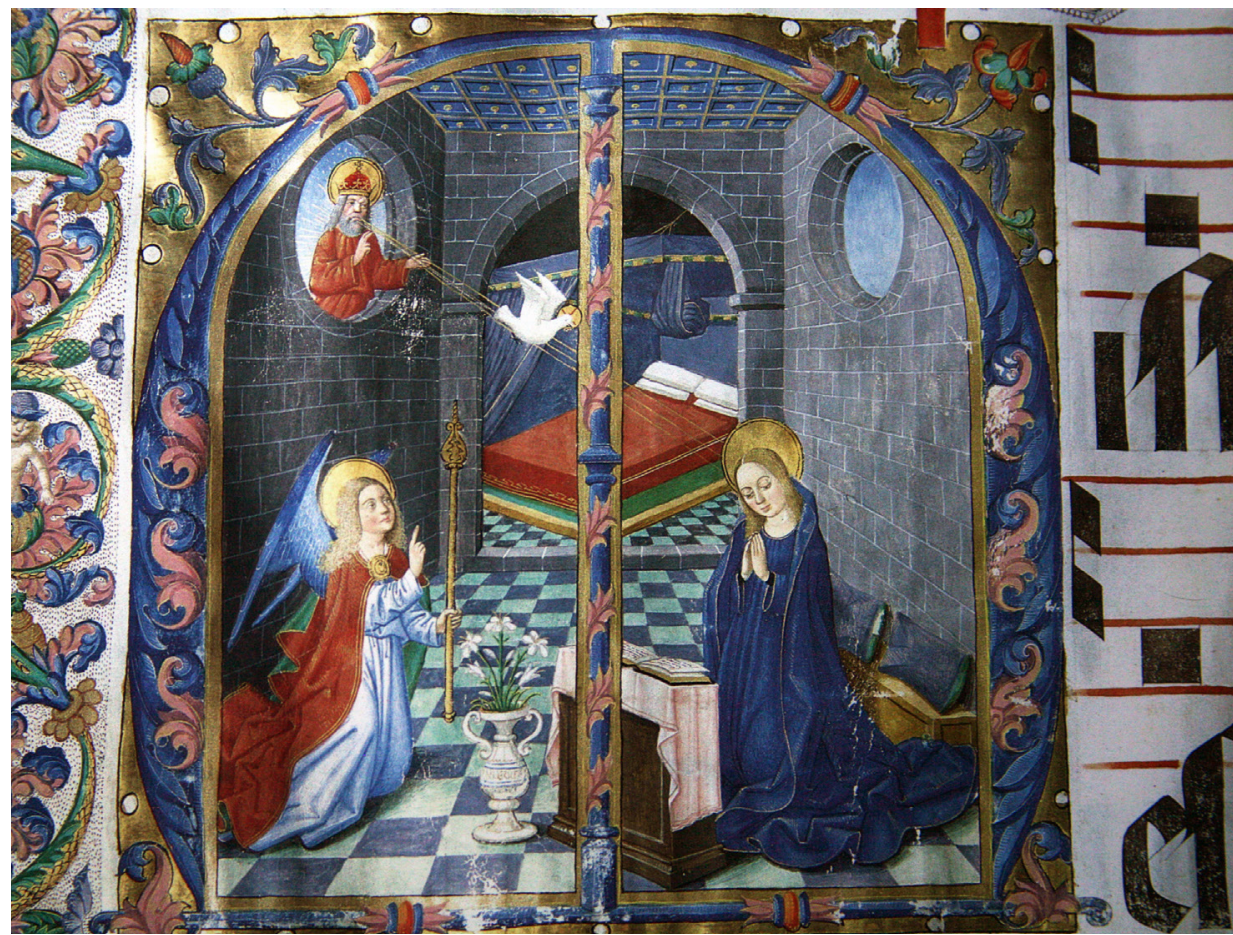

Figura 8. Detalle del cantoral nº. 5, Maestro de Osma (s. XV), desde la Purificación de la Virgen hasta la Anunciación, f. 114v. (fot. José lgnacio Palacios).

periodo trabajan en la edición de misales y cantorales Cristóbal Rodríguez ${ }^{116}, \mathrm{y}$ en las correcciones Pedro Colomo y el infante Pedro Palomar ${ }^{117}$.

El tercer apartado abarca el siglo XVII. En él las escasas compras proceden de Madrid ${ }^{118}$ y hay una menor producción de libros corales. También se extiende la costumbre de aunar en un solo volumen la misa y el oficio divino, y añadir hojas de ciertas cosas inexistentes, como eran las fiestas de santos recién canonizados (Teresa de Jesús e Ignacio de Loyola ${ }^{119}$. Entre los copistas figuran Juan Ortiz de Aldama y su hijo Pedro, y sobre todo Cristóbal Salazar ${ }^{120}$. A partir de 1682 se

116 Édith Weber, Le Concile de Trente et la Musique. De la Réforme à la Contre-Réforme, Paris, 2008, pp. 121 y 126.

117 ACBO, LCF, t. 1511 , ff. 242 v., 356 v. y 442 v.

118 ACBO. $L A C$, t. 12 , ff. 137,142 v. y 143 v., y $L C F$, t. 1578 , ff. 281 y 318 v.

119 ACBO. $L C F$, t. 1578, f. 341.

120 ACBO. $L A C$, t. 11, f. 90 v. 


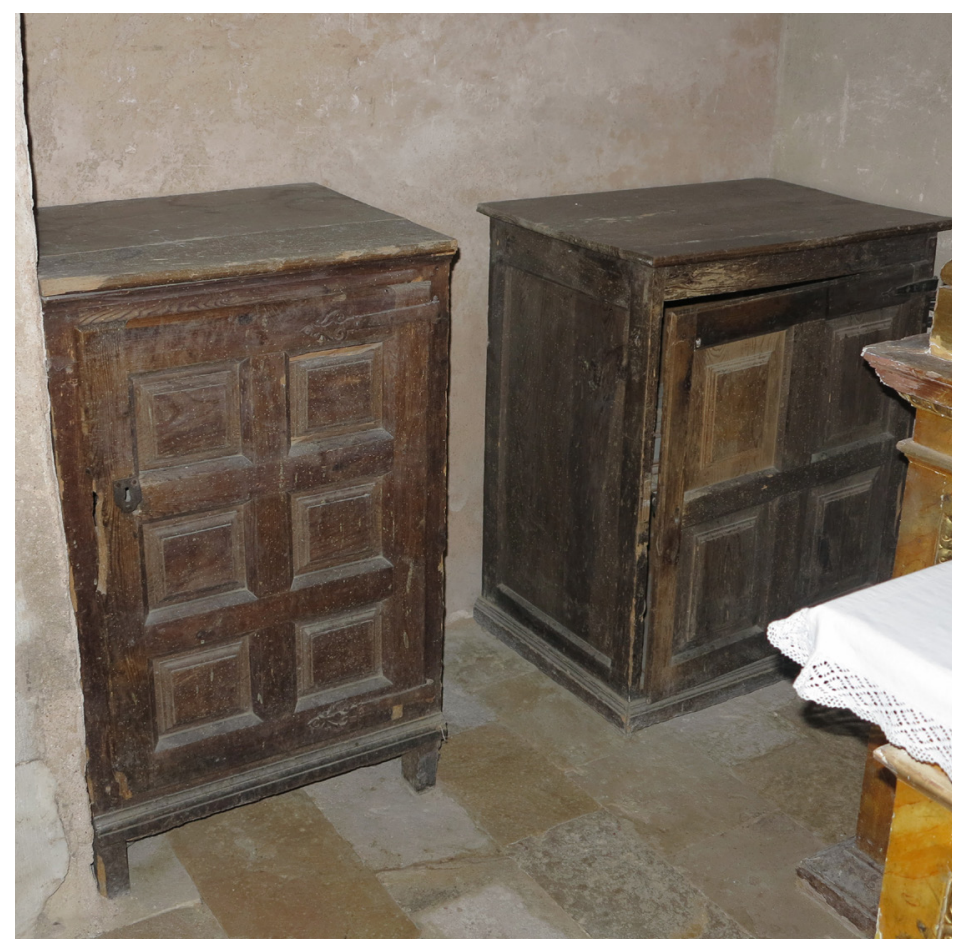

Figura 9. Antiguos

cajones para guardar los libros de coro (fot. José Ignacio Palacios).

incorpora Sebastián de Peralta, vecino de Cintruénigo, al que encargan un libro de oficios e himnos según las nuevas directrices ${ }^{121}$.

El tránsito hacia la nueva centuria viene marcado por el empleo del papel de marca ${ }^{122}$ y la introducción en 1702 del nuevo himnario de Urbano VIII a cargo del librero Jerónimo Rubio. Una vez acabadas estas reformas comienzan la de los misales en $1706^{123}$, y encargan al librero Pedro de Alhambra siete cantorales y seis libros con letanías e himnos, corriendo la escritura musical por cuenta de

${ }^{121}$ Mercedes Agulló y CoBo, La imprenta y el comercio de libros en Madrid (s. XVI-XVIII), tesis doctoral, Universidad Complutense de Madrid, 1992, pp. 182 y 231. Sebastián de Peralta pudo ser hijo de Diego Miguel de Peralta, alumno de Pedro Marqués y activo en Madrid desde 1734.

122 ACBO, $L C F$, t. 1668 , s.f.

123 ACBO, $L A C$, t. 1 , f. $555 ; L A C$, t. 22.1, f. 298 y $L C F$, t. 1668 , s.f. 
Francisco Escalante ${ }^{124}$. Desde este instante se suceden diversas intervenciones y añadidos de salterios y libros de coro en $1774^{125}$, 1790 y $1792^{126}$.

Las adiciones en los cantorales son puntuales en el siglo XIX con la incorporación de las fiestas del Sagrado Nombre de Jesús y de María en 1835. ${ }^{127}$ De nuevo en 1858, el cabildo manda introducir cambios en un grupo de libros de facistol y compra unos nuevos breviarios en $1867^{128}$. En 1884 Damián Sanz fue el encargado de supervisar junto al secretario capitular si podían dar uso a algunos cantorales, pero concluyen que la música que contienen estaba desfasada y respondían al modelo de canto monástico. $\mathrm{Y}$ a partir de entonces quedarán paulatinamente en desuso ${ }^{129}$.

\section{CONCLUSIONES}

Tomando como referente la catedral de Burgo de Osma, vemos que existen puntos comunes con otras muchas seos hispanas y en un espacio de tiempo concreto acerca de los espacios que ocupaban los archivos capitulares. En todas ellas el concepto de biblioteca surge a finales del siglo $\mathrm{XV}$, bajo el patrocinio y sensibilidad de prelados y capitulares humanistas. La estancia de la libraría es fácil identificar puesto que estaba situada en el claustro en una estancia independiente para albergar códices, libros e incunables, independiente de la contaduría. La ampliación del número de ejemplares librarios hizo necesario su control y contar con locales más idóneos y amplios, de ahí que a comienzos del siglo XVIII se unifican y se establecen normas de funcionamiento interno.

Desgraciadamente, al igual que ha ocurrido en tantos archivos, el patrimonio librario y musical de esta catedral ha desaparecido o ha menguado con el paso de los años, por el deterioro de las obras o por el cambio de gusto estético que conllevaba aparcar ciertos volúmenes. En el plano musical, la catedral de Burgo de Osma puede presumir de tener una magnífica colección medieval, mientras el repertorio de los siglos XVI al XVII es más bien escaso, y en cambio está mejor

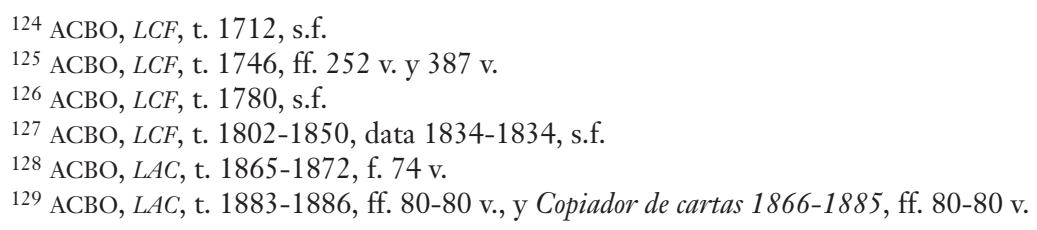


representado desde la segunda mitad del siglo XVIII hasta la actualidad ${ }^{130}$. Asimismo, hay un aspecto diferenciador, relativo al tratamiento y responsabilidad que el cabildo otorga a los libros polifónicos y de canto llano frente a las partituras, que obedecía a cuestiones de índole práctica.

La documentación existente permite contextualizar la producción musical propia y la circulación de obras, así como las características de los autores, cuya música perdura en el tiempo como un modelo de polifonía. Este es el caso de Guerrero, Navarro, Victoria, Aguilera de Heredia y a nivel local Juan García de Salazar, Bernardo Pérez, Alejo Sierra e Hilarión Eslava. También el contenido de las cartas y actas capitulares confirman que las impresiones inicialmente eran a costa de los compositores, hasta que en el siglo XVIII corre por cuenta de un editor, sin que falten a partir de entonces los tratados teóricos impresos. Por otro lado, hemos identificado los copistas, encuadernadores y libreros de los libros de canto llano; son un conglomerado de volúmenes esenciales en la vida litúrgica de cualquier catedral, que evidencian un empobrecimiento de la escritura de la música monódica, al mismo tiempo que se observa una evolución en el empleo del pergamino al papel y de la escritura aquitana a los valores mensurales.

Después de diversos avatares en el tiempo, en la actualidad tanto el archivo general como el musical ocupan el mismo sitio. La biblioteca cuenta con número importante de documentos, códices e incunables, mientras que el archivo musical consta de 70 cantorales ordenados correlativamente y 1824 registros de obras musicales, con un total de 1541 partituras en 47 cajas y 283 piezas repartidas en los ocho libros de polifonía.

130 Por poner un ejemplo, ver GarcíA-Bernalt Alonso, Catálogo de Música de la Capilla de la Universidad de Salamanca, Salamanca, 2013, p. 27. 
